\title{
Interfacial Structure of Erbium Oxide Layer on SUS316 Substrate Formed by MOCVD Method
}

\author{
Takayuki Shinkawa ${ }^{1}$, Kenji Matsuda ${ }^{2, *}$, Yoshimitsu Hishinuma ${ }^{3}$, \\ Katsuhiko Nishimura ${ }^{2}$, Teruya Tanaka ${ }^{3}$, Takeo Muroga ${ }^{3}$ and Takahiro Sato ${ }^{4}$ \\ ${ }^{1}$ Graduate School of Science and Engineering for Education, University of Toyama, Toyama 930-8555, Japan \\ ${ }^{2}$ Graduate School of Science and Engineering for Research, University of Toyama, Toyama 930-8555, Japan \\ ${ }^{3}$ National Institute of Fusion Science, Toki 509-5292, Japan \\ ${ }^{4}$ Hitachi High-Technologies Corporation, Hitachinaka 312-0057, Japan
}

The $\mathrm{Er}_{2} \mathrm{O}_{3}$ layer fabricated by MOCVD method on SUS316 substrates before and after hydrogen permeation test were investigated to know their surface morphology and structure by SEM and TEM. The surface morphology of this layer was granular structure with size of about $0.3-0.6 \mu \mathrm{m}$ in diameter. According to the cross sectional TEM (X-TEM) observation, the $\mathrm{Er}_{2} \mathrm{O}_{3}$ layer with $1-1.3 \mu \mathrm{m}$ thickness was formed on SUS316 substrate by MOCVD method in this research and no remarkable defects or cracks were detected. $\mathrm{The} \mathrm{Er}_{2} \mathrm{O}_{3}$ layer had the columnar structure and their mean width was $0.3-0.5 \mu \mathrm{m}$, and it is also in good agreement with mean width of a single column measured by TEM observation. The growth direction of $\mathrm{Er}_{2} \mathrm{O}_{3}$ column was $\langle 110\rangle_{\mathrm{Er} 2 \mathrm{O} 3}$, which is the same with as each sample before and after hydrogen permeation test, it strongly suggested that the $\mathrm{Er}_{2} \mathrm{O}_{3}$ is a better candidate material for insulating coating of a liquid lithium blanket. [doi:10.2320/matertrans.M2014287]

(Received August 6, 2014; Accepted September 24, 2014; Published November 14, 2014)

Keywords: Erbium oxide, metal organic chemical vapor deposition (MOCVD), microstructure, hydrogen permeation test, advanced breeding blanket system

\section{Introduction}

There is the ITER project to introduce fusion plasma reactor for the next generation, and many related research projects are also proceeding to develop new system in Japan. ${ }^{1)}$ The magnetic confinement typed fusion reactor system will be mainly constructed by high magnetic field superconducting magnet system, vacuum vessel, plasma heating instrument, tritium breeding and shielding blanket system and so on. In the breeding blanket system, there are three kinds of tritium breeding methods, which are Solid $\left(\mathrm{Li}_{2} \mathrm{TiO}_{3}\right)$, liquid metal lithium ( $\mathrm{Li}$ or $\left.\mathrm{Pb}-\mathrm{Li}\right)$ and fluoride molten salts (FLiNaK or FLiBe). The Magneto-HydroDynamic (MHD) pressure drop is a critical issue for liquid metal breeding blanket systems. ${ }^{2,3)}$ An electrical potential is induced in liquid metal flowing in a duct and channel perpendicular to a magnetic field. ${ }^{4}$ ) The electric current which induced in the liquid metal is short-circuited in the liquid metal. The interaction between electric current and magnetic field generates Lorentz force, and this force is applied against the liquid metal flow direction. ${ }^{4)}$ An electrically insulating coating with oxide ceramics is one of the attractive methods for reducing the MHD pressure drop due to the restraining of the Lorentz force. Because a ceramic material has higher electrical resistivity in order to cut the interaction between electric current and magnetic field.

Some ceramic materials such as $\mathrm{CaO}, \mathrm{Y}_{2} \mathrm{O}_{3}, \mathrm{CaZrO}_{3}, \mathrm{AlN}$ and $\mathrm{Er}_{2} \mathrm{O}_{3}$ have been studied as candidates for the insulator coating. ${ }^{5,6)}$ The electrical insulator materials for liquid metal breeding blanket system are required thermal stability for high temperature above $800^{\circ} \mathrm{C}$, hydrogen permeation, corrosion resistance for liquid $\mathrm{Li}$ and $\mathrm{Pb}-\mathrm{Li}^{2}{ }^{2}$ Erbium oxide $\left(\mathrm{Er}_{2} \mathrm{O}_{3}\right)$ was selected as one of the best candidate materials

*Corresponding author, E-mail: matsuda@eng.u-toyama.ac.jp for insulating coating because of high compatibility with liquid Li and high electrical resistivity. ${ }^{5)}$ Furthermore, it was found that $\mathrm{Er}_{2} \mathrm{O}_{3}$ layer can significantly suppress hydrogen permeation. Thus, we are convinced that $\mathrm{Er}_{2} \mathrm{O}_{3}$ is a suitable coating material as not only the electrical insulator but also tritium leakage barrier materials. ${ }^{7)}$ Various Physical Vapor Deposition (PVD) technologies have therefore been developed for small coating $\mathrm{Er}_{2} \mathrm{O}_{3}$ layer on blanket structural materials. ${ }^{8,9)}$ Recently, Hishinuma et al. succeeded to form $\mathrm{Er}_{2} \mathrm{O}_{3}$ thin coating via the Metal Organic Chemical Vapor Deposition (MOCVD) process as a new coating technology for broad and complicated shaped areas for the advanced breeding blanket applications. ${ }^{10,11)}$ MOCVD process is a vapor phase epitaxy growth which is synthesized via vapor phase from metal organic complex, and is very easy technique to form homogeneous coating layer on the broad and complex shaped area. Various characterization of the $\mathrm{Er}_{2} \mathrm{O}_{3}$ coating via MOCVD process has been showed lower roughness of coating surface and adhesion strength for nanoscratch test. ${ }^{12)}$ In the view point of practical usage, hydrogen permeation property of $\mathrm{Er}_{2} \mathrm{O}_{3}$ coating is also one of the important factors to apply the insulator coating for the advanced breeding blanket system.

In this study, we investigated that surface morphology and microstructure before and after hydrogen permeation test of the $\mathrm{Er}_{2} \mathrm{O}_{3}$ coating which formed on Stainless steel 316 (SUS316) substrate using MOCVD process.

\section{Experimental}

$\mathrm{Er}_{2} \mathrm{O}_{3}$ coating samples on SUS 316 substrates were fabricated by the MOCVD apparatus in National Institute for Fusion Science (NIFS). ${ }^{10,11)}$ MOCVD apparatus in NIFS consists of three main components such as a vaporizer, a gold furnace typed quartz tube reactor and an exhaust system. The 
Before hydrogen permeation test
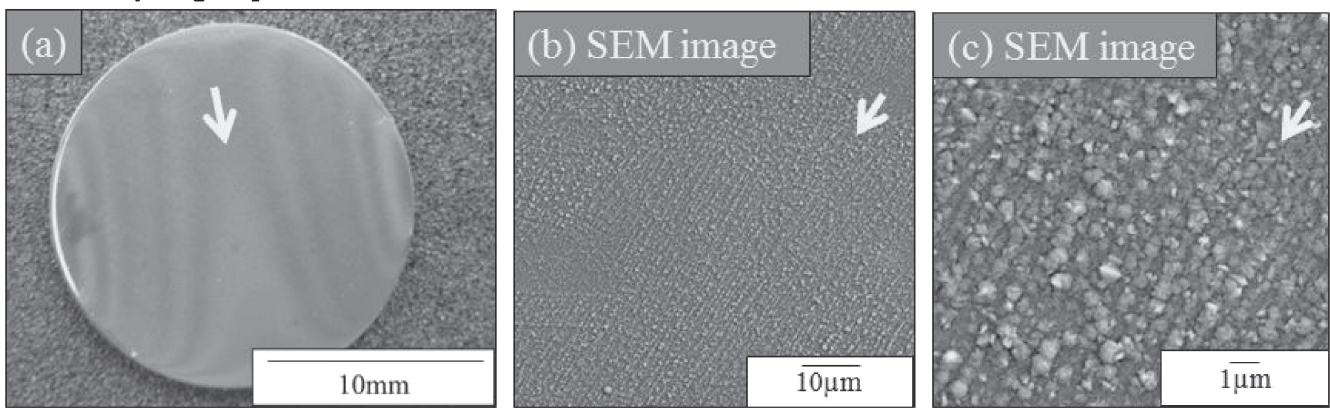

After hydrogen permeation test
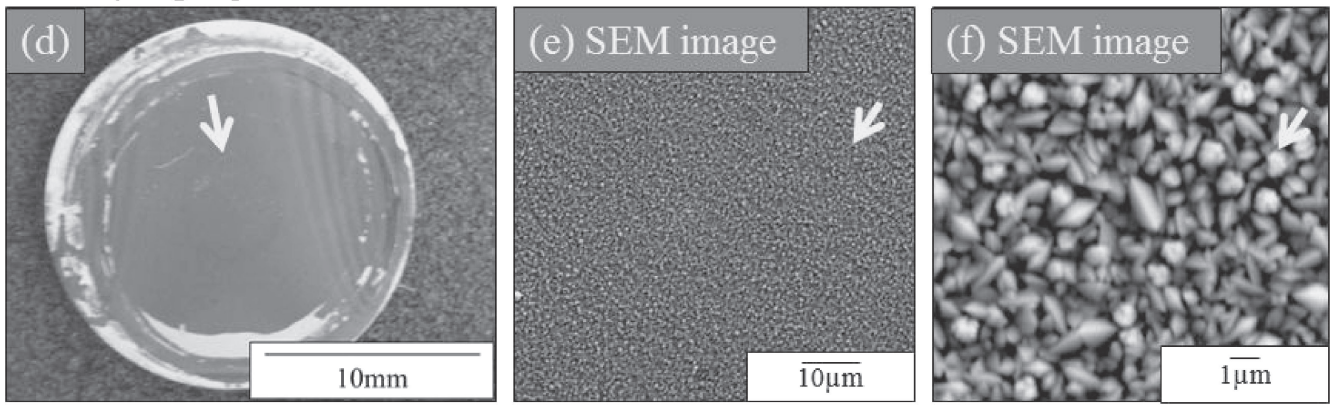

Fig. 1 Surface morphologies and microstructures for $\mathrm{Er}_{2} \mathrm{O}_{3}$ films. (a) and (d) their outlooks. (b), (c), (e) and (f) SEM images. (a)-(c) before, and (d)-(f) after hydrogen permeation test.

metal organic complex was vaporized in the vaporizer and introduced into the reactor by the argon carrier gas. All supplying gas lines were heated at $523 \mathrm{~K}$ by the ribbon heater to prevent the metal organic complex solidification. The vaporized complex reacted with oxygen gas in the reactor and then metal oxide layer was grown on the substrate by the phase epitaxial growth process. In this study, the $\operatorname{Er}(\mathrm{IBPM})_{3}$ (isobutyrylpivaloylmethane) complex, which was one of the $\beta$-diketone complexes, was selected because of the lower melting point and better pyrolysis behavior compared with the $\operatorname{Er}(\mathrm{DPM})_{3}$ complex. $^{10)}$ The substrate was used a commercial SUS316 disc plate, it was placed into the temperature plateau region of the reactor. The size of metal substrate was $17 \mathrm{~mm}$ for the diameter and $1 \mathrm{~mm}$ for the thickness. MOCVD process is controlled by the deposition pressure, the mass flowing rates of complex carrier and oxygen gases and deposition conditions such as temperature and time. The deposition pressure was 30 torr. The mass flowing rates of complex carrier and oxygen gases were fixed to 300 and $50 \mathrm{sccm}$, respectively. The deposition condition was $773 \mathrm{~K}$ for 3 hours.

The hydrogen permeation test was performed by the following as, the coating sample was set between the high pressure and low pressure chamber (high pressure side; coating surface, low pressure side; SUS316 substrate). ${ }^{13)}$ The hydrogen penetrated slowly from high to low pressure side chamber. Hydrogen gas of $4-40 \mathrm{kPa}$ was introduced in the high pressure chamber and the amount of hydrogen permeation to the low pressure chamber was evaluated from the magnitude of the response of the quadrupole mass spectrometer (QMS). The measurement was performed at 723-923 K.

After the hydrogen permeation test, the sample discs took out from the machine, and provided for analysis of micro- structure or the hydrogen permeation test. Scanning, transmission, and scanning-transmission electron microscopes (SEM (Hitachi S3500), TEM (Topcon EM-002B), STEM (Hitachi HD7200)) were used for analysis of microstructure in samples.

Small tips of cross sectional TEM (X-TEM) samples for TEM observation were prepared perpendicular to the sample surface and parallel to gas flow on MOCVD by FIB method. FIB was Hitachi FB-2100. The dimension of small tip of XTEM sample was about $12 \mu \mathrm{m} \times 2 \mu \mathrm{m}$, and its thickness is less than $100 \mathrm{~nm}$. The accelerating voltage of FIB was $40 \mathrm{kV}$, $\mathrm{Ga}+$ ion beam size was $520 \mu \mathrm{m}$ in the first for rough milling, and then changed to the smallest beam size of $15 \mu \mathrm{m}$ for final gentle milling.

\section{Results and Discussions}

\subsection{Surface morphology of samples by optical and SE microscopy}

Discs for samples fabricated by MOCVD method were observed by optical microscopes. In Fig. 1(a) and (d), the gas flows were indicted by white arrows in each figure. According to the XRD analysis in the previous report, only $\mathrm{Er}_{2} \mathrm{O}_{3}$ phases can be detected and no other oxides exist on these samples. ${ }^{12)}$ A rainbow reflection is corresponding by the difference of thickness of $\mathrm{Er}_{2} \mathrm{O}_{3}$ film for each sample, and it depends on the direction of gas flow. SEM images of Fig. 1 (e) and (f), a sample after hydrogen permeation test shows larger size of particles on the sample than those in a sample before that test of Fig. 1(b) and (c). The mean size of particles on the former and latter ones were about 0.31 and $0.59 \mathrm{~nm}$, respectively. It will be probably the grain grows during those tests because of the temperature increasing about $773 \mathrm{~K}$. 

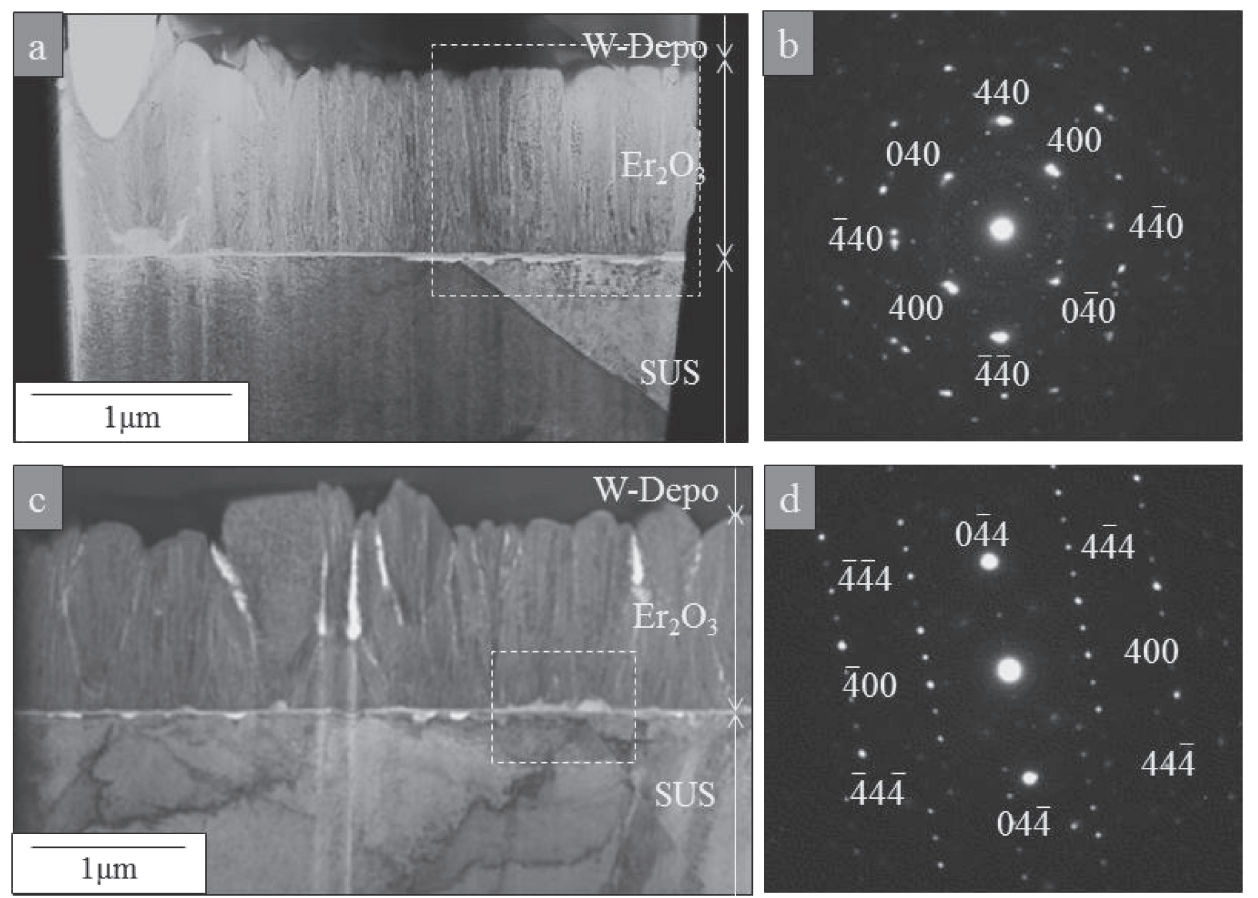

Fig. 2 TEM bright field images and SAED patterns obtained for X-TEM samples prepared from the surface of Er $\mathrm{O}_{3}$ film. (a) and (b) before, and (c) and (d) after hydrogen permeation test.

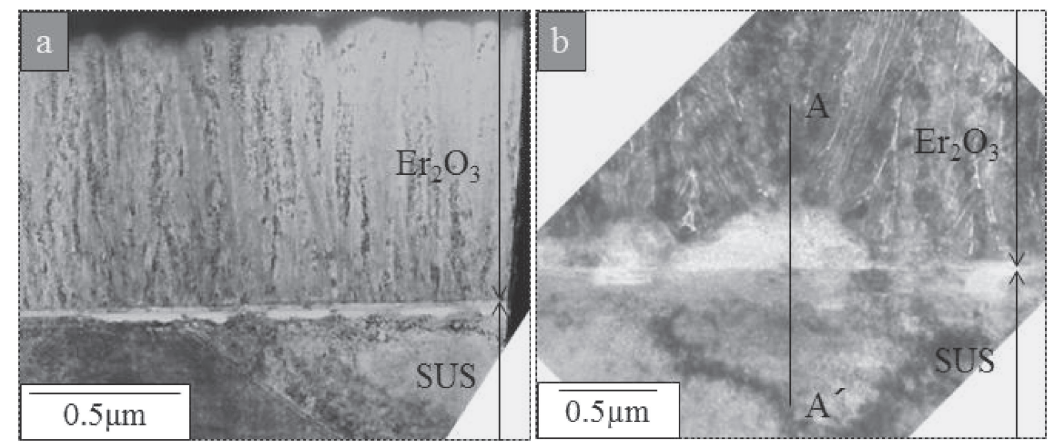

Fig. 3 (a) and (b) are enlarged TEM bright field images marked by dotted squares in Fig. 2 (a) and (c).

\subsection{Cross sectional samples for TEM prepared by FIB method}

Samples before and after hydrogen permeation test were cut for TEM sample by FIB method to prepare X-TEM sample. Figure 2 shows their TEM images. Three layers of SUS substrate, $\mathrm{Er}_{2} \mathrm{O}_{3}$ and white layer between them can be seen in Fig. 2(a) and (c). The thickness of $\mathrm{Er}_{2} \mathrm{O}_{3}$ layer for both samples were almost the same as about $1-1.3 \mu \mathrm{m}$ to each other, (in detail, $0.9 \pm 0.1 \mu \mathrm{m}$ before test and $1.3 \pm$ $0.2 \mu \mathrm{m}$ after test). The columnar structure can be seen in the $\mathrm{Er}_{2} \mathrm{O}_{3}$ layer in each sample and its width was $0.26 \mu \mathrm{m}$ and $0.54 \mu \mathrm{m}$ for the samples before and after hydrogen permeation test, respectively, and it is also the similar to the particle size on the surface obtained for each sample by SEM in Fig. 1. The detailed observation of interface between the $\mathrm{Er}_{2} \mathrm{O}_{3}$ and the substrate was performed for each sample. The growth direction of $\mathrm{Er}_{2} \mathrm{O}_{3}$ columns for each sample on X-TEM image was mostly parallel to the same direction of $\langle 110\rangle_{\mathrm{Er} 2 \mathrm{O} 3}$. This is in the good agreement with reports for $\mathrm{Er}_{2} \mathrm{O}_{3}$ thin films on the $\mathrm{Si}(001)$ substrate which has the crystallographic relationship with $(110)_{\mathrm{Er} 2 \mathrm{O} 3}$ plane, ${ }^{14,15)}$ because of small misfit between those crystal planes.

Figure 3 (a) and (b) show enlarged pictures marked by white dotted squares in Fig. 2(a) and (c). These are clearly indicated the existence of a bright layer between $\mathrm{Er}_{2} \mathrm{O}_{3}$ layer and SUS substrate in both samples. Chemical analysis was performed for the region indicated a A-A' line in Fig. 3(b) using by EDS. Figure 4 shows its result. Light elements, for example, $\mathrm{O}, \mathrm{C}$ and $\mathrm{N}$ were not visible in this line analysis, so these elements were negligible in this figure. The unknownlayer between $\mathrm{Er}_{2} \mathrm{O}_{3}$ and substrate includes $\mathrm{Fe}$ and $\mathrm{Cr}$. The inserted figure is the EDS profile obtained for the mid-point of unknown layer, and it includes oxygen. Figure 5 shows STEM images and STEM-EDS maps obtained for the same sample of Fig. 3(b). An unknown layer is clearer than a conventional TEM image and it has complicated morphology between $\mathrm{Er}_{2} \mathrm{O}_{3}$ and substrate. The comparison between BF-STEM and HAADF-STEM images, crystal columns of $\mathrm{Er}_{2} \mathrm{O}_{3}$ grow like as the dendrite in cast metal samples, which has just on direction, and there are also some nucleation sites in the unknown layer marked by white arrows. Figures 5 (c) 


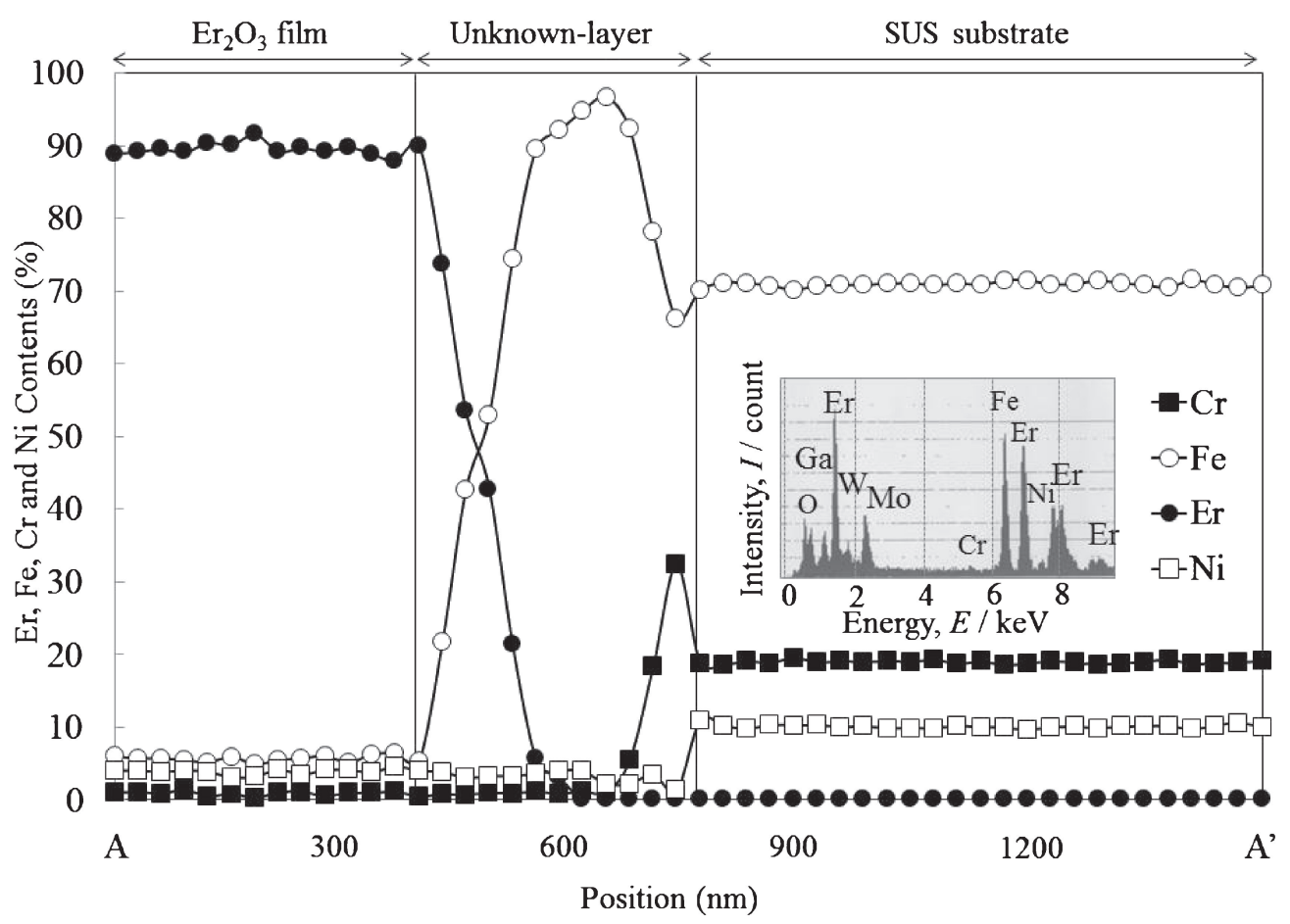

Fig. 4 EDS profiles for Er, Fe, $\mathrm{Cr}$ and $\mathrm{Ni}$ elements obtained for the line A-A' in Fig. 3(b).
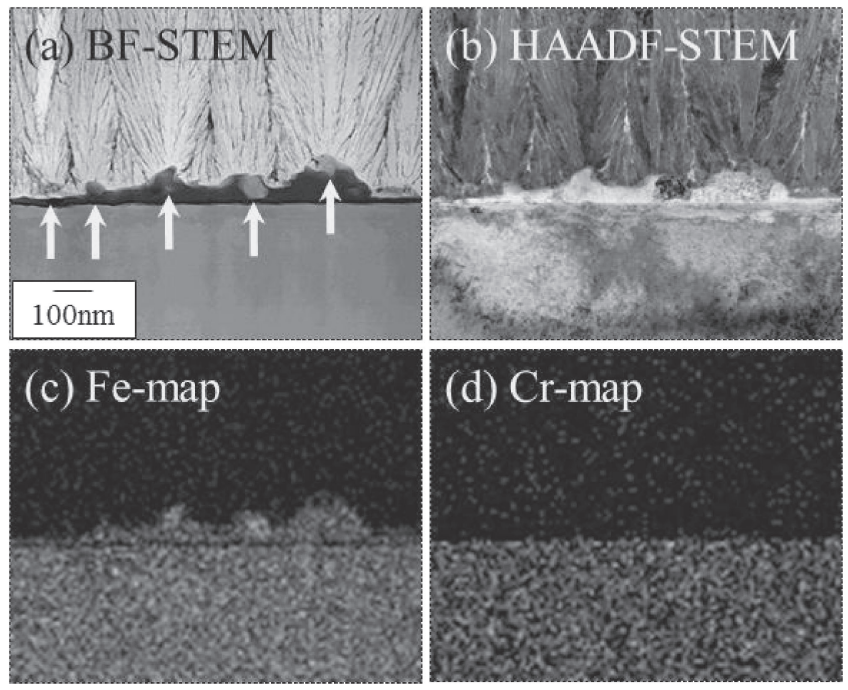

Fig. 5 (a) BF- and (b) HAADF-STEM images and EDS maps of (c) Fe and (d) Cr obtained for the X-TEM sample of Fig. 3(b).

and (d) show Fe-K $\alpha$ and $\mathrm{Cr}-\mathrm{K} \alpha$ EDS maps. According to these EDS maps and the line analysis of Fig. 4(a), the unknown layer mainly consists of $\mathrm{Fe}$ and $\mathrm{O}$, and includes $\mathrm{Cr}$ little bit. These oxides are probably formed by oxidation during preparation of sample polishing before fabrication of $\mathrm{Er}_{2} \mathrm{O}_{3}$ film by MOCVD. It is noted that elements in the substrates, for example, $\mathrm{Fe}, \mathrm{Cr}$ or $\mathrm{Ni}$ were not detected from $\mathrm{Er}_{2} \mathrm{O}_{3}$ layer. It means that elements in substrate do not diffuse into films during MOCVD processing and hydrogen permeation test. Some Fe-oxides act as the nucleation site for $\mathrm{Er}_{2} \mathrm{O}_{3}$ core, and it is mostly formed dendritic mechanism like as molten metals. And then, it grows perpendicular to the substrate to form columnar structure and these are filled up by branching of columns and those coarsening.

\section{Conclusions}

Morphology and microstructure of $\mathrm{Er}_{2} \mathrm{O}_{3}$ layer fabricated by MOCVD method on SUS316 substrates before and after hydrogen permeation test were investigated by SEM and TEM. Results obtained are as follows:

(1) The surface morphology was granular structure with size of about $0.3-0.6 \mu \mathrm{m}$ in diameter. Its result was in good agreement with the X-TEM observation. The thickness of the $\mathrm{Er}_{2} \mathrm{O}_{3}$ layer with $1-1.3 \mu \mathrm{m}$, and it consists of many columns of $\mathrm{Er}_{2} \mathrm{O}_{3}$ with $0.3-0.5 \mu \mathrm{m}$.

(2) The growth direction of $\mathrm{Er}_{2} \mathrm{O}_{3}$ column was $\langle 110\rangle_{\mathrm{Er} 2 \mathrm{O} 3}$, and it is the similar to the result for $\mathrm{Er}_{2} \mathrm{O}_{3}$ layer on the $\mathrm{Si}$ (001) substrate, although some oxide layers existed between $\mathrm{Er}_{2} \mathrm{O}_{3}$ layer and substrate.

(3) The microstructure of $\mathrm{Er}_{2} \mathrm{O}_{3}$ layer did not include any remarkable defects or difference between samples before and after hydrogen permeation test, and elements of $\mathrm{Fe}, \mathrm{Cr}$ or $\mathrm{Ni}$ in the substrates were not detected from $\mathrm{Er}_{2} \mathrm{O}_{3}$ layer. It means that the $\mathrm{Er}_{2} \mathrm{O}_{3}$ layer is good candidate for the fusion plasma reactor for the next generation.

\section{Acknowledgement}

A part of this research was supported by the general collaboration project of NIFS (\#KEMF045), and the research project of University of Toyama 2013. The authors thank Ms. Akiko Hirata (Univ. Toyama) for operating FIB to prepare X-TEM samples.

\section{REFERENCES}

1) S. Tanaka, Y. Ohara and H. Kawamura: Fusion Eng. Des. 51-52 (2009) 299-307. 
2) S. Malang, H. U. Borgstedt, E. H. Farnum, K. Natesan and I. V. Vitkovski: Fusion Eng. Des. 27 (1995) 570-586.

3) J.-H. Park, T. Domenico, G. Dragel and R. Clark: Fusion Eng. Des. 27 (1995) 682-695.

4) L. Barleon, V. Casal and L. Lenhart: Fusion Eng. Des. 14 (1991) 401412.

5) D. L. Smith, J. Konys, T. Muroga and V. Evtikhin: J. Nucl. Mater. 307311 (2002) 1314-1322.

6) B. A. Pint, P. F. Tortorelli, A. Jankowski, J. Hayes, T. Muroga, A. Suzuki, O. I. Yeliseyeva and V. M. Chernov: J. Nucl. Mater. 329-333 (2004) 119-124.

7) T. Chikada, A. Suzuki, Z. Yao, D. Levchuk, H. Maier, T. Terai and T. Muroga: Fusion Eng. Des. 84 (2009) 590-593.

8) A. Sawada, A. Suzuki, H. Maier, F. Koch, T. Terai and T. Muroga: Fusion Eng. Des. 75-79 (2005) 737-740.

9) F. Koch, R. Brill, H. Maier, D. Levchuk, A. Suzuki, T. Muroga and H.
Bolt: J. Nucl. Mater. 329-333 (2004) 1403-1406.

10) Y. Hishinuma, T. Tanaka, T. Tanaka, T. Nagasaka, S. Yoshizawa, Y. Tasaki and T. Muroga: J. Nucl. Mater. 417 (2011) 1214-1217.

11) Y. Hishinuma, T. Tanaka, T. Tanaka, T. Nagasaka, Y. Tasaki, A. Sagara and T. Muroga: Fusion Eng. Des. 86 (2011) 2530-2533.

12) Y. Hishinuma, S. Murakami, K. Matsuda, T. Tanaka, Y. Tasaki, T. Nagasaka, A. Sagawa and T. Muroga: Plasma Fusion Res. 7 (2012) 4051271.

13) Y. Hishinuma, T. Tanaka, T. Tanaka, T. Nagasaka, Y. Tasaki, S. Murakami, K. Matsuda, A. Sagara and T. Muroga: Fusion Sci. Technol. 60 (2011) 1131-1134.

14) R. Xu, Y. Y. Zhu, S. Chen, F. Xue, Y. L. Fan, X. J. Yang and Z. M. Jiang: J. Cryst. Growth 277 (2005) 496-501.

15) X. Wang, Y. L. Zhu, M. He, H. B. Lu and X. L. Ma: Acta Mater. 59 (2011) 1644-1650. 